\title{
HIV/AIDS among Migrant Workers in Malaysia
}

\author{
Najimudeen $\mathbf{M}^{*}$, Myo Hla Myint, Mie Mie Cho Win, Mahfuza Akter \\ International Medical School Management and Science University, Malaysia
}

$\begin{array}{ll}\text { DOI: } 10.36348 / \text { sijog.2020.v03i01.001 } & \text { |Received: } 13.01 .2020 \text { | Accepted: } 20.01 .2020 \text { | Published: } 24.01 .2020\end{array}$

*Corresponding author: Mohamed Najimudeen

\section{Abstract}

Female migrant workers are susceptible for economic exploitation, physical violence and sexual abuse. They are at risks of sexually transmitted diseases, unwanted pregnancy, illegal termination of pregnancy and related problems. They also spread the diseases knowingly and unknowingly. There are about five millions registered and undocumented migration workers are in Malaysia. The Malaysian government is committed to stop the illegal trafficking of women and under aged girls. The health education programme and screening procedures are important to prevent the spread of HIV/AIDS.

Keywords: Migrant workers, HIV/AIDS. STD, Human trafficking, Malaysia.

Copyright @ 2020: This is an open-access article distributed under the terms of the Creative Commons Attribution license which permits unrestricted use, distribution, and reproduction in any medium for non-commercial use (NonCommercial, or CC-BY-NC) provided the original author and source are credited.

\section{INTRODUCTION}

The term migrant workers has different meaning in different parts of the world. The United Nation's definition is persons outside their country of origin for 12 months or more. According to the International Labour organisation (ILO) there were 232 million international migrants in the world in the year 2014 [1]. There were more than 30 million migrant workers in the Asia and the Pacific region in the year 2013 [2]. The female migrant workers are vulnerable to sexual violence, economic exploitation, physical and verbal abuse and labour rights violations [3].

\section{METHODS}

This is a literature survey pertaining to the HIV/AIDS among migration workers in Malaysia

\section{DISCUSSION}

The migrant workers are more susceptible for HIV/AIDS compared to the local populations. The immigrants are separated from their partners and families. They are isolated due to language and cultural barriers. They look for friendship. The loneliness force them to alcoholism, illicit substance use and multiple sex partners. They do not have access to awareness and screening programme. These make them vulnerable to HIV/AIDS and related illnesses. They are easily infected and transmit the disease to the spouse and others [4]. Female domestic migrant workers are at risks of STD, unwanted pregnancy, illegal termination of pregnancy and related problems [5] Female migration workers play an important role in HIV spread [6] Irregular migrant workers do not have access to HIV/AIDS awareness campaigns on the electronic, print and other mass media. Even the message provided by television/radio advertisements did not make an impact as, in the popular perception. They did not convey the gravity of the epidemic. The general low level of awareness about HIV/AIDS can be traced to the limited level of NGO intervention on the issue in rural areas. Some 87 per cent of the migrants interviewed said there were no awareness campaigns in the host country about HIV/AIDS prevention [7] A study was conducted by the UNDP, in partnership with people living with HIV/AIDS (PLWHA) groups in the AsiaPacific region, Nearly $67 \%$ percent of the participants stated that migration was the main factor vulnerable to HIV/AIDS. They admitted that they were not aware the mode of spread and danger of the disease and health education programme could have protected them [8]. Malaysian perspective Rapid economic growth of many sectors in Malaysia attracted huge number of workers from nearby countries. The workers had migrated legally and illegally $[9,10]$. Malaysia is attractive to migration workers in terms of food, culture, tolerance and employment opportunities [11]. It respects the diversity of ethnicity and cultural believes. There are about 4-6 millions of documented and undocumented migrant workers are employed in Malaysia. Most of 
Najimudeen M et al; Sch Int J Obstet Gynec, Jan. 2020; 3(1): 1-3

them involve in construction sites, agriculture, factory and domestic work [12]. A significant number of females are employed as sex workers. Substantial number of them are victims of human trafficking. They were promised an attractive employment but ended in bars, karaoke, clubs, massage parlors and brothel centres. Their passports and personal documents were forcefully taken by the illegal operators. These innocent victims are highly vulnerable for all the sexually transmitted illnesses (STI) but not access to safe sex or HIV screening [13]. The influx of large number of migrant workers from the adjacent countries is a health threat in Malaysia. Therefore the government of Malaysia made three annual mandatory medical check up for foreign workers from the date of arrival [14] Some of the female domestic workers are exposed to long working hours with less payments. They suffer from physical, psychological and sexual abuse of their employers. Unregistered illegal immigrants fear of police arrest. They are exploited forced to prostitution. Some of the women to earn some extra money become as commercial sex workers on their own and function independently or through agents many hundreds of female sex workers form Philippine, Thailand and Myanmar come to Malaysia on one month tourist visa and engage in sex trade. Their health status is unknown and they are capable of transmitting sexual diseases. The HIV screening for migrant workers in Malaysia is a very successful programme. In the year 1998, there were 565,737 workers tested and 178 persons found to be positive. From 1998-2004, a total number of $4,158,034$ people were tested and 1,192 workers were found to be positive [15]. Policy of mandatory testing is compulsory to apply for a work or renew their contract. If they were found to be positive for HIV, they were deported within 3 days [16]. In Malaysia, sex trade and related activities are illegal and liable for punishment under Penal Code section 372 [17]. In Malaysia, between 2001 and June 2005, nearly 34,000 marriages between local men and foreign women and 11,112 local women got married to foreign men [18]. Maria Grazia Giammarinaro, the United Nations Special Rapporteur on trafficking had visited Malaysia in February 2015. She noted that large number of young foreign women and children are illegally trafficked into Malaysia with many false promises knowingly and unknowingly. They were forced to marry much older men. They were promised affluent jobs but forced into sex work [19]. Fortunately the government of Malaysia is making a tremendous effort to eradicate trafficking by complying to the minimum standards of the Trafficking Victims Protection Act's (TVPA). This made the US Department of State's Trafficking in Persons Report to upgrade Malaysia from Tier 3 (lowest rank) in 2014 to Tier 2 (Middle grade) [20] The Malaysian government had taken significant efforts to curb the problems of human trafficking. In 2007, the law on anti-trafficking and anti-smuggling of migrants was introduced. A council against trafficking and smuggling of migration (MAPO) was established under a provision in this Act
[21]. The Act was further broadened in November 2010 to include all actions involved in acquiring or maintaining the labour or services of people through coercion [22]. In recent years, there has been an increase in the number of convictions under this law and efforts made to increase public awareness on trafficking [23].

\section{ACKNOWLEDGEMENTS: NIL}

\section{DECLARATIONS \\ Funding: No Fundings}

Conflict of Interest: No Conflicts of Interest

Ethical Approval: Not Applicable

\section{REFERENCES}

1. Wolffers, I., Fernandez, I., Verghis, S., \& Vink, M. (2002). Sexual behaviour and vulnerability of migrant workers for HIV infection. Culture, Health \& Sexuality, 4(4), 459-473.

2. Labour migration in Asia and the Pacific. Available at: http://www.ilo.org/asia/areas/labourmigration/langeen/index.htm

3. International Labour Migration, Gender, and Sexual and Reproductive Health and Rights in East Asia, Southeast Asia and the Pacific. Available

at: http://www.arrow.org.my/uploads/Migration_Wor kingPaper.pdf.

4. Wolffers, I., Fernandez, I., Verghis, S., \& Vink, M. (2002). Sexual behaviour and vulnerability of migrant workers for HIV infection. Culture, Health \& Sexuality, 4(4), 459-473.

5. Jordal, M., Wijewardena, K., Öhman, A., Essén, B., \& Olsson, P. (2014). Negotiating respectability: migrant women workers' perceptions of relationships and sexuality in free trade zones in Sri Lanka. Health care for women international, 35(6), 658-676.

6. Simonet, D. (2004). The AIDS Epidemic and Migrants in South Asia and South-East Asia. International Migration, 42(5), 35-67.

7. Al-Najjar, S. (2002). Women Migrant Workers in Bahrain, International Migrant Papers, 47. Geneva: International Labour Office.

8. A rapid survey conducted electronically in 2004 among people living with HIV/AIDS (PLWHA) networks across the Asia-Pacific by UNDP Regional HIV and Development Programme, New Delhi (UNDP REACH), and the Asia-Pacific PLWHA Resource Centre (APPRC).

9. Labour Department Peninsular Malaysia. (2014). Statistics PLKS by citizens and sector In: Statistics of Employment and Labour. Malaysia: Ministry of Human Resources. 24-25.

10. Bardan, S. (2014). Practical guidelines for employers on the recruitment, placement, 
Najimudeen M et al; Sch Int J Obstet Gynec, Jan. 2020; 3(1): 1-3

employment and repatriation of foreign workers in Malaysia. Malaysian Employers Federation.

11. Abdul-Aziz, A. R. (2001). Bangladeshi migrant workers in Malaysia's construction sector. Asia Pacific Population Journal, 16(1), 3-22.

12. Chan, C. K. (2015). Malaysia: Migration, Rights, and Health Security. Presentation at: New Paradigms for a Changing Migration Landscape Conference to Commemorate International Migrants Day. Bangkok: Chulalongkorn University.

13. The Jakarta Post. (2006). Malaysia Promises to Act Against Human Trafficking. 22 March 2006

14. Ministry of Health. (2006). Mandatory medical checks for alien workers in first two years, 19 April 2006. http://www.moh.gov.my/MOH Portal/newsFull.

15. HIV Screening of Migrant Workers in Malaysia, 1998-2004. (2006). Source: Ministry of Health.

16. Kurus, B. (1998). Migrant labour: the Sabah experience. Asian Pac Migration Journal, 7(2):281-295.

17. Laws of Malaysia Act 574 Penal Code Incorporating all amendments up to 1 January 2006. Available at: http://www.agc.gov. my/Akta/Vol.12/Act574.pdf.

18. Chee, H. L. (2011). Chapter 13-International marriages in Malaysia: issues arising from state policies and processes. In: Jones GW, Hull TH, Mohamad M, editors. Changing marriage patterns in Southeast Asia: economic and socio-cultural dimensions: Routledge Contemporary Southeast Asia Series, 185-201.

19. Brown, V. (2015). UN Special Rapporteur: Malaysia's migrant workers often exploited, trafficked, prostituted. The Star Online.

20. Trafficking in persons report 2015. 2015. Available http://www.state.gov/documents/organization/226 847.pdf

21. Council for Anti-Trafficking in Persons and AntiSmuggling of Migrants. Available at: http://mapo.bernama.com/mapo.php.

22. Anti-trafficking in persons and anti-smuggling of migrants Act 2007. As at November 2014. Available at: http://www.agc.gov. my/Akta/Vol.14/Act670.pdf. (last accessed 13/07/2015).

23. Lasimbang, H. B., Tong, W. T., \& Low, W. Y. (2016). Migrant workers in Sabah, East Malaysia: The importance of legislation and policy to uphold equity on sexual and reproductive health and rights. Best Practice \& Research Clinical Obstetrics \& Gynaecology, 32, 113-123. 